\title{
An unusual cryptogeobiid from southeastern Brazil revisited (Opiliones, Laniatores, Gonyleptoidea)
}

\author{
Adriano Brilhante Kury' \& Laura Regina Caramori ${ }^{2}$ \\ 1 Universidade Federal do Rio de Janeiro (UFRJ), Museu Nacional (MN), Departamento de Invertebrados. Rio de Janeiro, RJ, Brasil. \\ ORCID: http://orcid.org/0000-0002-8334-6204. E-mail: adrianok@gmail.com \\ 2 Universidade Federal do Paraná (UFPR), Setor de Ciências Biológicas, Departamento de Zoologia (DZ00). Curitiba, PR, Brasil. \\ ORCID: http://orcid.org/0000-0002-4970-9200. E-mail: laurarcaramori@gmail.com
}

\begin{abstract}
The monotypic genus Bunostigma Mello-Leitão, 1935 is herein revisited. A detailed redescription of its type-species, Bunostigma singulare Mello-Leitão, 1935 from Rio de Janeiro state, eastern Brazil, is herein presented, providing in depth knowledge of this genus. Bunostigma is most closely related to Cryptogeobius Mello-Leitão, 1935, and as this genus, it has a stout complex apophysis on male coxa IV, lacking, however, a second complex on the stigmatic area. Bunostigma has an oblique elongate malleus, similar to that of Zalanodius Mello-Leitão, 1936 (as opposed to a globular malleus in (ryptogeobius). Bunostigma singulare has short legs, with some sexual dimorphism on its stoutness, a dorsal scutum entirely unarmed and an ocularium with an accessory central mound, although unarmed.
\end{abstract}

Keywords. Arachnida; Brazilian Atlantic Forest; Neotropical; Rio de Janeiro.

\section{INTRODUCTION}

Amidst the soil-dwelling Neotropical harvestmen, the recently described family Cryptogeobiidae includes 55 valid species (Kury et al., 2021) distributed in the eastern Brazilian Atlantic Forest, extending somewhat to the interior to Paraguay (Kury, 2003). Cryptogeobiids are small laniatorean Gonyleptoidea with male genitalia characterized by a hammer + lamina parva as opposed to other such as cosmetids and gonyleptids (which possess a ventral plate). They are typically short-legged, although Pseudopachylus and immediate related genera sport sexual dimorphism on the length of femur IV, which resembles the Mitobatinae (Kury, 2014). Bunostigma singulare possesses (1) an unusual bicolor pattern of body (in most cryptogeobiids, when the body is bicolor, the scutal areas are darker than the rest), (2) a greatly developed retroventral apical apophysis on Cx IV which distorts overall outline of stigmatic area as to make it roughly triangular (as opposed to T-shaped in most members of the family), (3) a stout Ti IV on male, armed with thick spiniform apophyses. All those features set $B$. singulare apart from the run-of-the-mill Cryptogeobiidae.

\section{MATERIAL AND METHODS}

Descriptions of colors use the standard names of the 267 Color Centroids of the NBS/IBCC Color System (http://people.csail.mit.edu/jaffer/Color/ Dictionaries\#nbs-iscc) as described in Kury \& Orrico (2006). Scanning Electron Microscopy was carried out with a JEOL JSM-6390LV at the Center for Scanning Electron Microscopy of Museu Nacional/UFRJ. All measurements are in millimeters (mm). Morphological terminology for cryptogeobiids follows Kury (2014), body outline categories are from Kury \& Medrano (2016), penial macrosetae follow Kury \& Villarreal (2015).

Abbreviations are: MNRJ (Museu Nacional, Rio de Janeiro) RJ = Rio de Janeiro state. Other abbreviations used: $C L=$ carapace length, $C W=$ carapace width, $A L=$ abdominal scutum length, $A W=$ abdominal scutum width, $\mathrm{Cx}=\mathrm{coxa}, \mathrm{Tr}=$ trochanter, $\mathrm{Fe}=$ femur, $\mathrm{Pa}=$ patella, $\mathrm{Ti}=$ tibia, $\mathrm{Mt}=$ metatarsus, $\mathrm{Ta}=$ tarsus. FAp = Fasciolate hyaline apophyses (as described in Kury, 2014). Megaspines of pedipalpal cage: $\mathrm{i}=$ small, $\mathrm{I}=$ large, $\hat{I}=$ extremely large, much longer than the others. Tarsal formula: numbers of tarsomeres in tarsus I to IV, when an individual count is given, order is from left to 
right side (figures in parentheses denote number of tarsomeres only in the distitarsi I-II). All pre-2018 material was destroyed in the huge fire at the palace of MNRJ.

\section{Systematic background of Bunostigma}

Mello-Leitão (1935a: 10) described in Gonyleptidae Pachylinae the monotypic genus Bunostigma MelloLeitão, 1935 along with the type species Bunostigma singularis [sic] Mello-Leitão, 1935, from "Distrito Federal: Bico do Papagaio", providing an informative albeit far from complete illustration (authored by his assistant Roger P. Arlè) of the male habitus in dorsal view.
Kury (2003: 201) transferred this genus to the Gonyleptidae Tricommatinae. Kury \& Alonso-Zarazaga (2011: 58) noted that otípua (stígma = mark, spot) is neuter, making the genus also neuter, so the specific epithet should be accordingly declined as singulare. Finally, Kury (2014: 8) transferred Bunostigma along with several other genera from Tricommatinae to the new family Cryptogeobiidae in the immediate vicinity of Cryptogeobius Mello-Leitão, 1935.

In the present paper, we deepen the available morphological information on Bunostigma singulare MelloLeitão, 1935, a species of cryptogeobiid endemic from the Atlantic Forest of Rio de Janeiro state, southeastern Brazil.

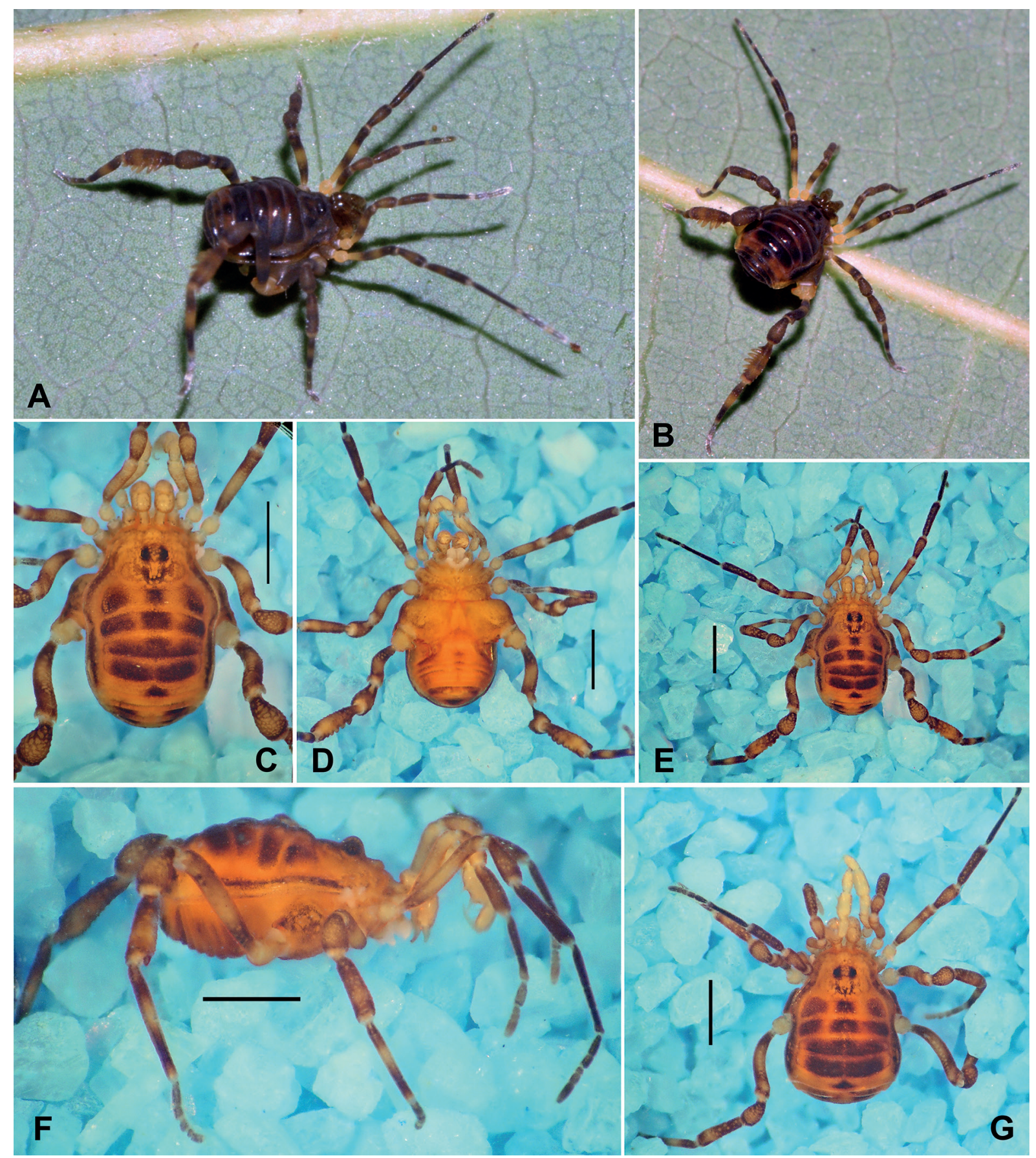

Figure 1. Habitus of Bunostigma singulare Mello-Leitão, 1935. (A) Male, in vivo at Tinguá, RJ. (B) Same, another view. (C) Male (MNRJ 7679) habitus dorsal view. (D) Same, ventral view. (E) Same, panoramic view. (F) Same, dextrolateral view. (G) Female (MNRJ 7679) habitus dorsal view. Scale bars: A-G = 1 mm. All photographs by A.B. Kury. 


\section{Systematic accounts}

\section{Family Cryptogeobiidae Kury, 2014 Bunostigma Mello-Leitão, 1935}

Bunostigma Mello-Leitão, 1935a: 10. Type-species by original designation: Bunostigma singulare MelloLeitão, 1935.

Bunostigma - Mello-Leitão, 1935b: 98; Soares \& Soares, 1954: 239; Maury, 1993: 102; Kury, 2003: 201.

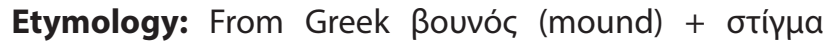
(mark; spot). Gender neuter.

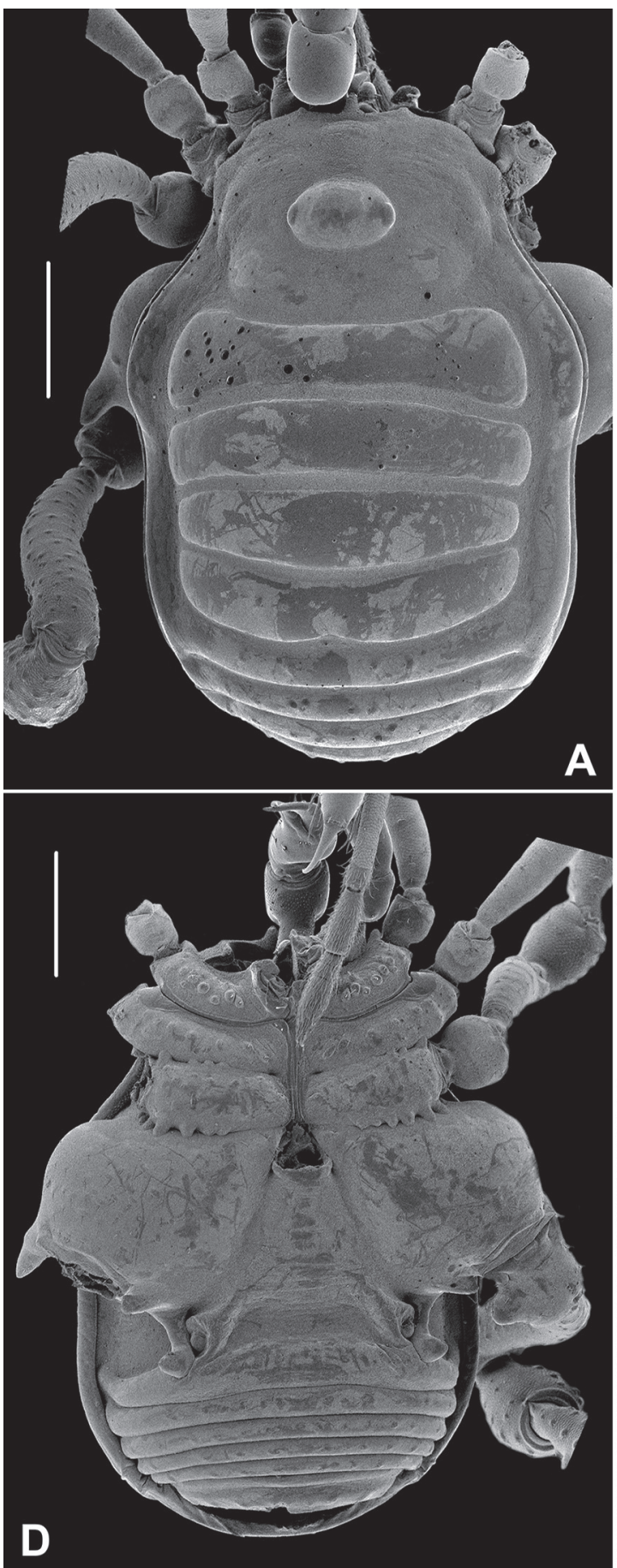

Placement: Bunostigma was originally in Pachylinae. Transferred to Tricommatinae by Kury (2003: 201) and to Cryptogeobiidae by Kury (2014).

Diagnosis: Ti IV of male with a row of six stout retrolateral spiniform apophyses (Figs. 1A-B; as opposed to all other cryptogeobiids). MS E2 considerably stouter (at least $5 \times$ longer) than E1 (Fig. 5D; contrasting with immediately related genera of Kury's 2014 group A). Tr IV of male with broad triangular median retrolateral apophysis (Figs. 1C-D, 2D; shared with Cryptogeobius, Spinopilar and Taquara). "Zebra-pattern" on the dorsal scutum: mesotergal areas dark brown, sharply contrasting
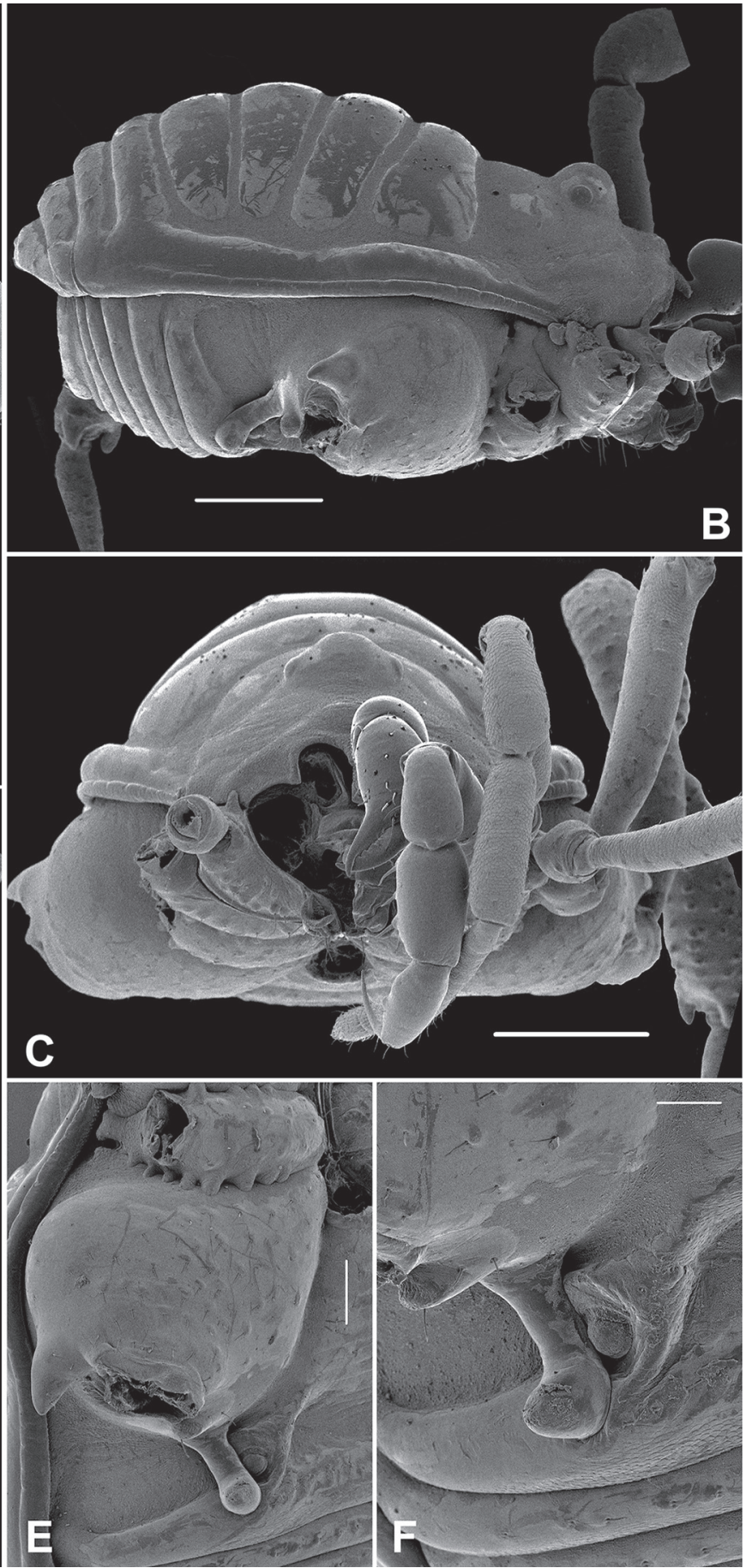

Figure 2. Bunostigma singulare Mello-Leitão, 1935, male (MNRJ 7679). (A) Body and proximal leg IV, dorsal view. (B) Body and Cx IV, dextrolateral view. (C) Habitus, without right side appendages, frontal view. (D) Body, ventral view. (E) Right Cx III IV, dorso-lateral view. (F) Same, magnified. Scale bars: A-D =500 $\mu \mathrm{m} ; E=200 \mu \mathrm{m} ; F=100 \mu \mathrm{m}$. 
with dark yellow background of the rest of the scutum (Figs. 1C, E, G; contrasting with Cryptogeobius and shared with Heteromeloleptes and Tibangara). Cx IV of male with elongate retrolateral apophysis which is applied on a socket on stigmatic area (Figs. 2A-B, D-F; exclusively shared with Cryptogeobius).

Included species: Only the type species.

\section{Bunostigma singulare Mello-Leitão, 1935 (Figs. 1-5)}

Bunostigma singularis Mello-Leitão, 1935a: 10, fig. 2. ₹ Incorrect originally applied gender declination. Species epithet is a Latin two-termination adjective of the third-declension (singularis, singularis, singulare). Bunostigma singularis - Soares, 1945: 370; Soares \& Soares, 1954: 240; Kury, 2003: 201.

Bunostigma singulare: Kury \& Alonso-Zarazaga, 2011: 58. Bunostigma singulare - Kury, 2014: 8, fig. 28N.

Type data: $\sigma^{x}$ lectotype, $10^{\pi} 39$ paralectotypes (MNRJ 41788) and 29 paralectotypes (MNRJ 42677), RJ, Rio de Janeiro, Parque Nacional da Tijuca, Bico do Papagaio peak, R. Arlé leg.

Other material examined: $1 \sigma^{\top}$ (MNRJ 4765) RJ, Rio de Janeiro, Parque Nacional da Tijuca, 03.iii.2001, A.P.L. Giupponi, D.R. Pedroso \& D.F. Almeida leg./10 1 \% (MNRJ 4950), same loc., Trilha da Caveira 08.ix.2001, A. Pérez \& A.P.L. Giupponi leg./10' 1 ㅇ (MNRJ 7679), same loc., close to Gruta do Belmiro, 15.vi.2012, A.B. Kury, C.M. Barros, D.R. Pedroso \& G.S. Miranda leg./10' (MNRJ 59054) Brasil, RJ, Nova Iguaçu, REBIO do Tinguá, surroundings of the seat $\left(-22.58199^{\circ},-43.43641^{\circ}\right.$, alt.: $\left.150 \mathrm{~m}\right)$ 07.i.2020, A.B. Kury, M.A. Medrano \& D.R. Pedroso leg.

Redescription, male (MNRJ 7679). Measurements: $\mathrm{CL}=0.83, \mathrm{CW}=1.20, \mathrm{AL}=1.34, \mathrm{AW}=1.69$. $\mathrm{Tr} \mathrm{I}=0.19$, $\mathrm{Fe} I=0.89, \mathrm{~Pa} I=0.45, \mathrm{Ti} I=0.60, \mathrm{Mt} \mathrm{I}=0.75, \mathrm{Ta} \mathrm{I}=0.69$; $\operatorname{Tr}\|=0.26, \mathrm{Fe}\|=1.25, \mathrm{~Pa}\|=0.57, \mathrm{Ti}\|=0.88, \mathrm{Mt} \|=0.99$, $\mathrm{Ta} I I=0.88 ; \mathrm{Tr} I I I=0.23, \mathrm{Fe} I I=1.16, \mathrm{~Pa} I I I=0.48, \mathrm{Ti} I I=0.83$, Mt III = 1.05, Ta III =0.77; $\operatorname{Tr} I V=0.32$, Fe IV $=1.08$, $\mathrm{Pa}$ IV $=0.58, \mathrm{Ti}$ IV $=0.95, \mathrm{Mt} \mathrm{IV}=1.31, \mathrm{Ta} \mathrm{IV}=0.72$

Dorsum (Figs. 1C, E-F, 2A-C): Dorsal scutum roughly theta type (bell-shaped): with laterals of carapace strongly widening posteriorly; mid-bulge noticeably short and only a little wider than the rest; abdominal scutum wider than carapace with sides almost parallel. Carapace with shallow C-shaped groove, entirely smooth; lateral ridges faintly marked; preocular mound very low, smooth. Ocularium low, elliptical (in dorsal view), with broad middle hump (in frontal view, Fig. 2C), situated in the middle of the carapace, entirely unarmed. Body outline in lateral view convex, continuous, without steep risings or pits. Lateral margins of scutum entirely smooth. Mesotergum divided into 4 areas. Area I with anterior and posterior margins straight and expanded on the laterals. Area II with anterior margin slightly arched frontwards and posterior margin straight. Area III with anterior margin straight, posterior arched backwards. Area IV with anterior margin arched backwards, following area III
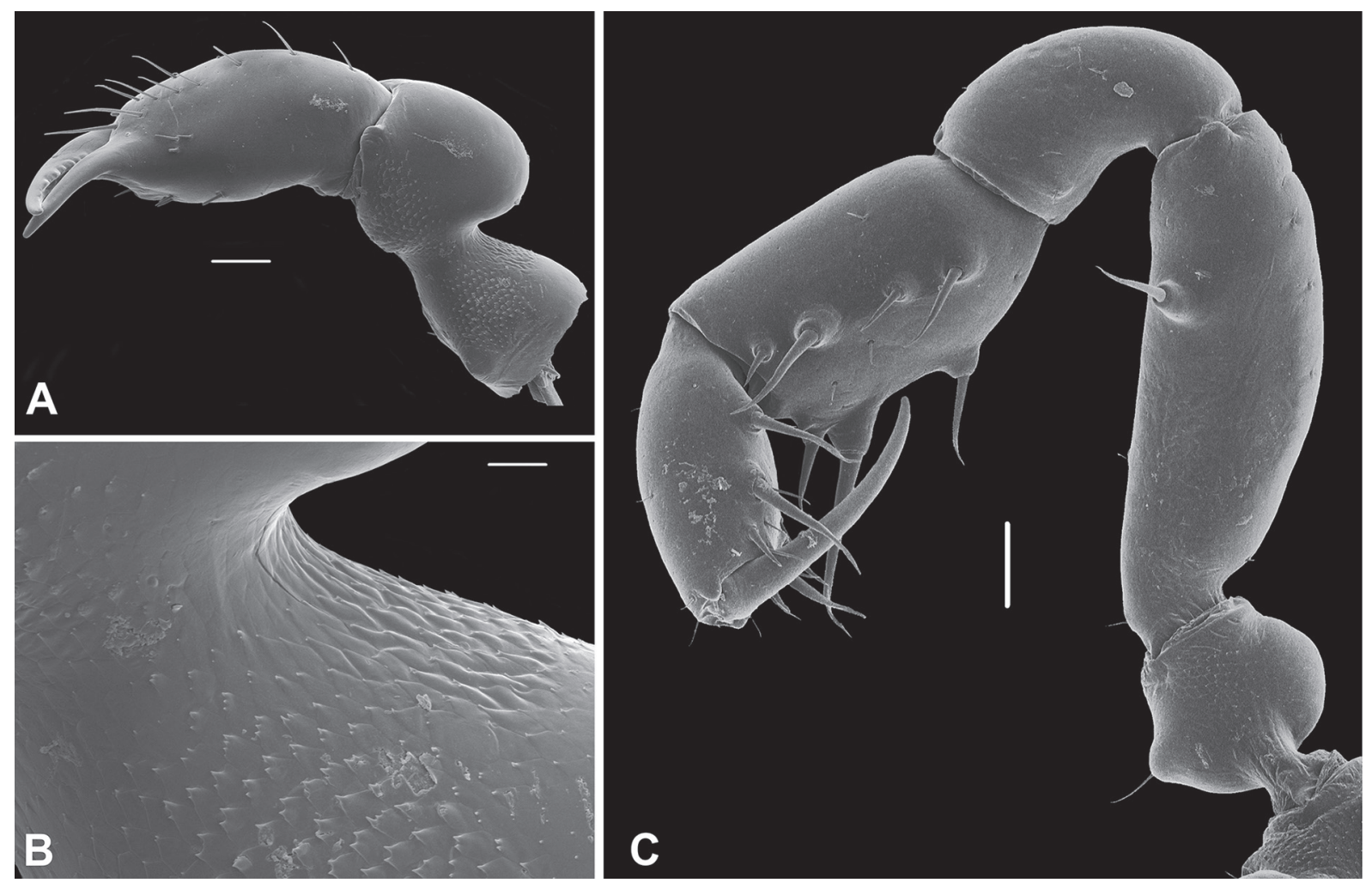

Figure 3. Bunostigma singulare Mello-Leitão, 1935, male (MNRJ 7679), mouth parts. (A) Right chelicera, mesal view. (B) Same, detail of cuticular sculpture of basichelicerite. (C) Right pedipalpus, mesal view. Scale bars: $A, C=100 \mu \mathrm{m} ; B=20 \mu \mathrm{m}$. 
and posterior margin also arched backwards, with small V-shaped cleft. All areas and free tergites entirely smooth and unarmed. Posterior border of dorsal scutum gently convex, with laterals merging into articular membrane along with free tergite I (Figs. 2A-B).

Venter (Figs. 1D, 2B, D-F): Coxae I-IV and stigmatic area only finely granular, with transverse rows of setiferous tubercles stouter anteriorly. Free sternites each with row of minute setiferous tubercles. Cx I to III transversal to main body axis; Cx II curved around Cx I, as long as Cx I, much longer than Cx III. Cx II and III delimit a narrow sternum. Maxillary lobe of Cx II as a small triangle. Cx I movable. Cx II linked to Cx III by four pairs of lateral tubercular bridges; Cx III linked to Cx IV by six to seven pairs of large lateral tubercular bridges. Cx IV oblique, as large as all others combined. Stigmatic area roughly triangular, only separated from Cx IV by a difference in height, fused to sternite II, with forked frames around the stigmata (Fig. 2D). Sternite II strongly thickened. Stigmata small, entirely longitudinal and framed by a complex formed by a forked structure + the retroapical apophysis of Cx IV (Fig. 2F). Cx IV with a well-developed wrench-shaped retroapical apophysis flanking the stigma and deeply embedded on the sternite II. Ventral complex without any lobes, expansions, fasciolate hyaline apophyses or cluster of modified setae.

Mouthparts (Figs. 3A-C): Basichelicerite with well-developed bulla, separated from peduncle by a narrow waist. Its mesal surface covered with patches of small denticles, but without any plectra. Cheliceral hand weak, monomorphic. Pp Tr with 1 large ventral megaspine, Fe with 2 small megaspines, Pa short, with one meso-distal setiferous tubercle, all of those with slender setae. Pedipalps stunt; Pp Fe cylindrical, only gently convex dorsally and moderately compressed, without stridulatory grid and with stout meso-distal setiferous tubercle. Spination of Pp cage: Ti mesal lili, ectal IÎl, Ta mesal Ili, ectal ili.
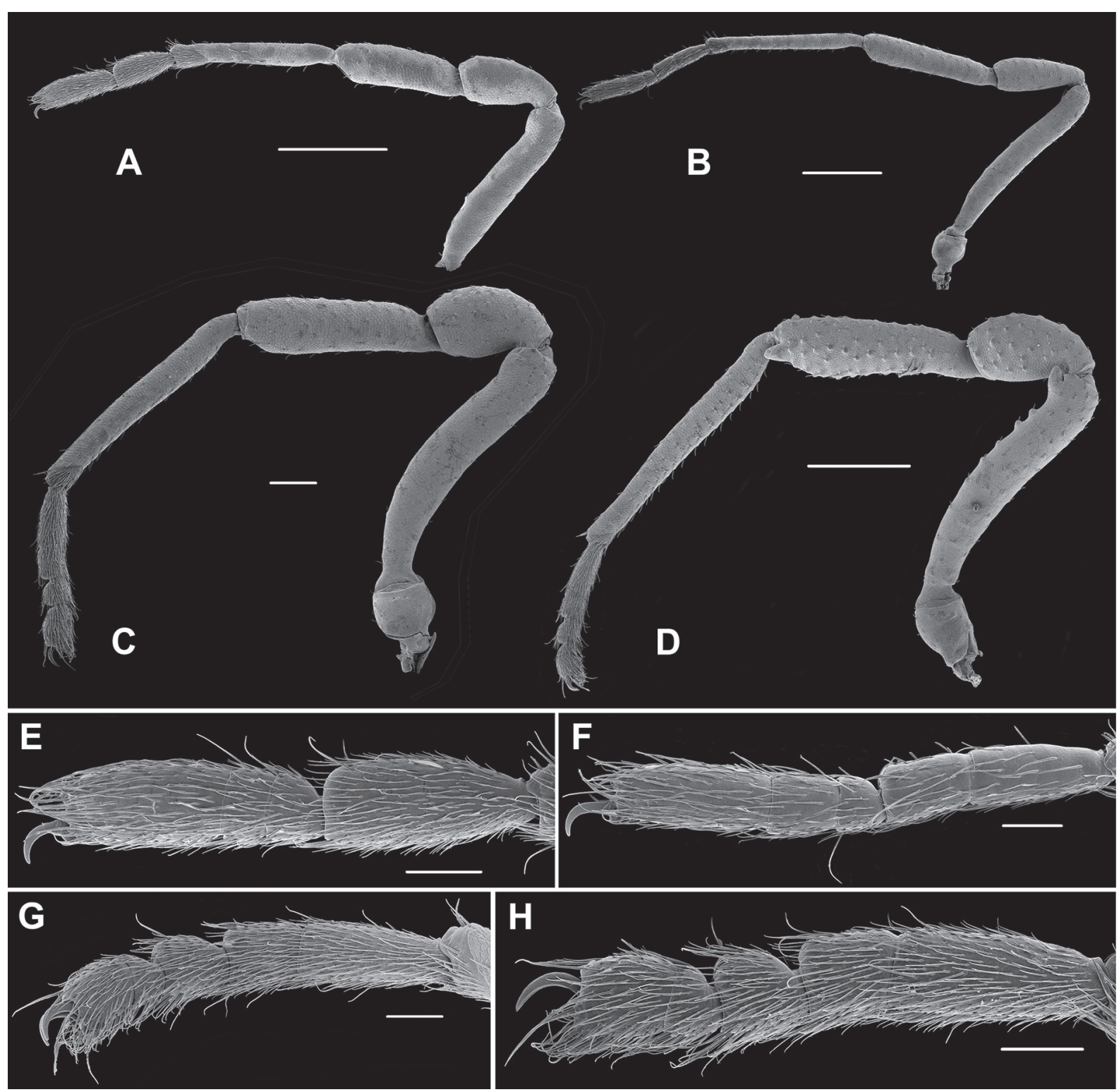

Figure 4. Bunostigma singulare Mello-Leitão, 1935, male (MNRJ 7679), right legs I to IV, prolateral view. (A) Leg I. (B) Leg II. (C) Leg III. (D) Leg IV. (E) Ta I. (F) Ta II. (G) Ta III. (H) Ta IV. Scale bars: A-D = $500 \mu \mathrm{m} ; \mathrm{E}-\mathrm{H}=100 \mu \mathrm{m}$. 

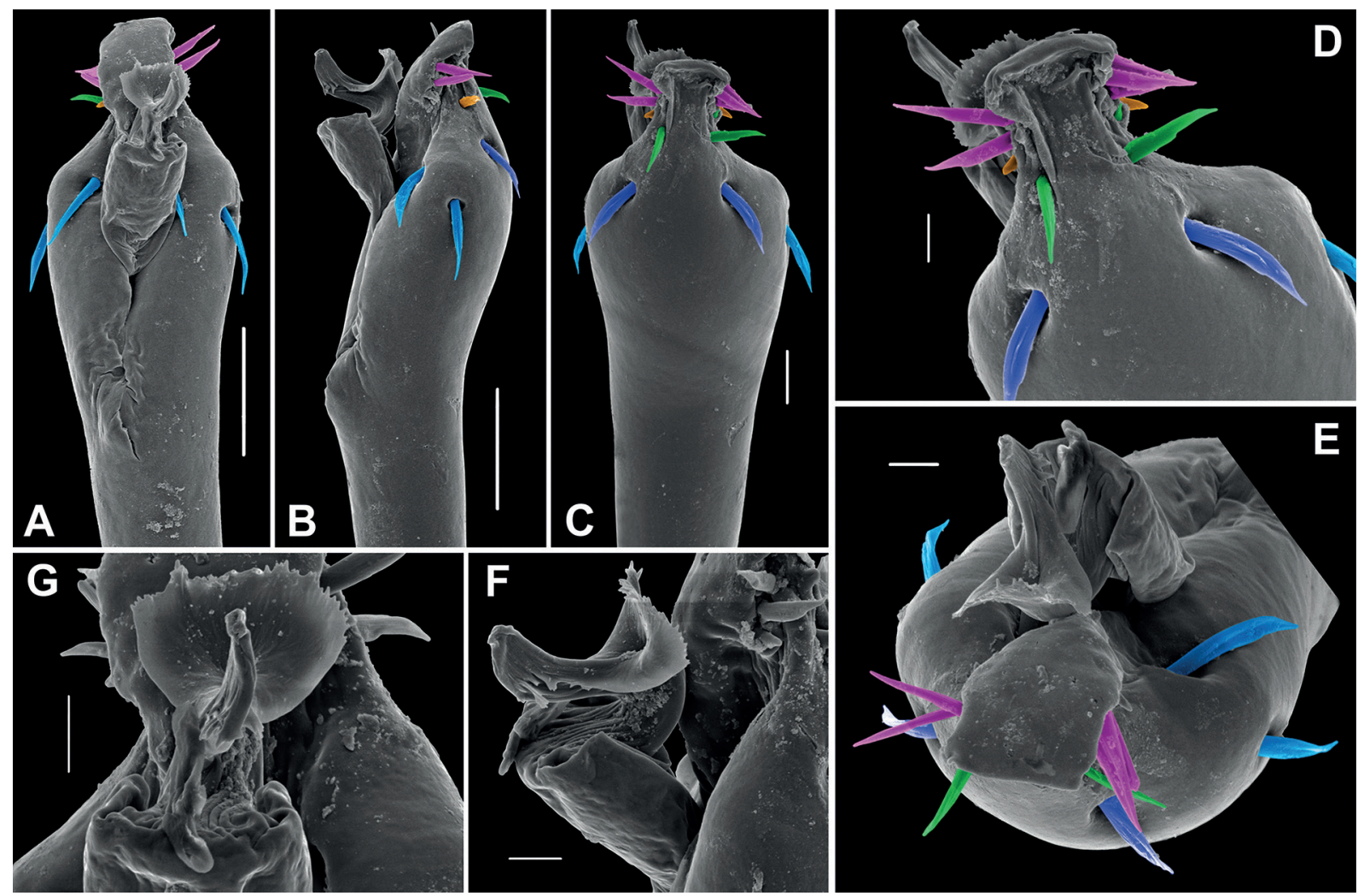

Figure 5. Bunostigma singulare Mello-Leitão, 1935, male (MNRJ 7679), genitalia, penis, pars distalis. (A) Dorsal view. (B) Dextrolateral view. (C) Ventral view. (D) Same, magnified. (E) Apical view. (F) Glans, dorsolateral view. (G) Same, dorsal view. Scale bars: A $=50 \mu \mathrm{m} ; \mathrm{B}-\mathrm{C}=20 \mu \mathrm{m}$; D-G $=10 \mu \mathrm{m}$. Color of macrosetae are: MS A (light blue), MS B (dark blue), MS C (magenta), MS D (orange) and MS E (green).

Legs (Figs. 1A-G, 4A-H): Legs I to III with all articles smooth, unarmed and without special modifications. Fe I-II substraight, III-IV strongly arched. Mt I-IV not spindled, divided into a short distal calcaneus (shortest in Mt IV) and a proximal astragalus. Cx IV: rather weak, expanding only slight laterally and posteriorly reaching mid area II, armed with a distal prodorsal conical apophysis. Tr IV: subsquare, with a large blunt median retroapical apophysis. Fe IV: cylindrical, arched, bearing a proventral row of setiferous tubercles on the distal half, growing stouter apically. Ti IV: uniformly incrassate, with one apical proventral spur and a row of six retrolateral spines (Fig. 1B). Tarsal counts (Figs. E-H): 4(3)/5(3)/5/5.

Male genitalia (Figs. 5A-G): Distal part of truncus slightly bent as an oblique malleus and an erect large lamina parva (LP). Dorsal malleus without hyaline button but with a long deep slit. Glans sac rigid, unfolded, gutter-shaped. Lamina parva prismatic, subrectangular (in ventral view) with rounded corners. Nine pairs of macrosetae (MS) A to E arranged as follows: MS A1 stout, inserted on dorso-apical surface of malleus, close to the base of LP. MS A2 stout, inserted on lateral surface of malleus, more proximal than A1. MS B1 as strong as A1-A2, located in the ventrally on malleus. MS C1-C3 short, smooth, inserted close to each other, located on the ventro-latero-distal edge of LP. MS D1 very short, located of the lateral surface of LP, close to C3. MS E2 similar in size to MS C, E1-2 forming a quadrangle on ventro-distal surface of LP, E2 much larger than E1. Stylus with a few distal folds, without dorsal accessory plate (DAPG), without head (but with tapering apex), slightly sinuous. Skirt ungrooved, semicircular, without an axis, radiating in dorsal view around a hollow center, with gently serrate margins.

Color (in alcohol): Dorsal and ventral body background vivid orange (centroid 48). Mesotergum with three longitudinal deep brown (centroid 56) stripes; with coalesce on areas III-IV. This darker shade also occurs on the lateral of scutum, middle of area $\mathrm{V}$ and lateral of free tergites and only very sparsely on the ventral surface. Color background of chelicerae, pedipalps and legs I to IV all light greenish yellow (centroid 101), densely reticulated and honeycombed with deep brown except on: trochanters I-IV, a few broad rings on femora I-IV and the most of pedipalps.

Sexual dimorphism: Male (MNRJ 7679) contrasted with female (MNRJ 7679). Female (Fig. 1G) in general color and proportions of body/appendages (except leg IV) very similar to male. Abdominal part of dorsal scutum is flaring (as opposed to parallel in males). Coxa without distal prodorsal and retroapical apophyses; trochanter and tibia IV unarmed.

\section{DISCUSSION}

Kury (2014: 14, fig. 7) recognized two main clades in Cryptogeobiidae, which he called A and B. The clade A contains several species with swollen or clavate 
podomeres in leg IV, while clade B contains the species mostly with a huge, hooked spine on the ocularium and a mitobatine-like sexual dimorphism on leg IV, where the podomeres in males, especially the femur IV, are straight and much elongate. Bunostigma belongs to the clade A, along with five other genera (Cryptogeobius Mello-Leitão, 1935, Heteromeloleptes Mello-Leitão, 1931, Paratricommatus Piza-Jr., 1943, Pseudophalangodes Roewer, 1912 and Zalanodius Mello-Leitão, 1936), and some undescribed terminals. Although Bunostigma was resolved as sister-group to Cryptogeobius, there is a wide morphological gap between both genera, mostly because of the unique scutum outline in Bunostigma and the strong armature of $\mathrm{Cx}$ and Tr IV in Cryptogeobius. Although monotypic genera are a noxious heirloom of the Roewerian System, this gap makes it more intuitive to leave Bunostigma singulare to stand alone in its own genus.

There are stumbling blocks hampering the attainment of a more refined phylogeny hypothesis for the Cryptogeobiidae: (1) most species are poorly known, and (2) there is a great number of undescribed species. Therefore, refining the morphological description of the type species of a genus is an important step towards this goal.

\section{ACKNOWLEDGMENTS}

This study has been supported by E-26/200.085/2019 (Apoio Emergencial ao Museu Nacional) from Fundação de Amparo à Pesquisa do Estado do Rio de Janeiro (FAPERJ), E-26/210.148/2019 (249116) (APQ1 - Auxílio à Pesquisa básica - 2019) from Fundação de Amparo à Pesquisa do Estado do Rio de Janeiro (FAPERJ), 306411/2015-6 (Produtividade em Pesquisa) from the Conselho Nacional de Desenvolvimento Científico e Tecnológico (CNPq), 430748/2018-3 (Chamada MCTIC/ CNPq No 28/2018 - Universal) from the Conselho Nacional de Desenvolvimento Científico e Tecnológico (CNPq) to ABK. The SEM micrographs were taken in the SEM Lab of Marine Diversity of the MNRJ (financed by PETROBRAS), with the kind assistance of Beatriz Cordeiro and Camila Messias. Two anonymous reviewers are acknowledged for constructive criticism.

\section{AUTHORS' CONTRIBUTIONS}

ABK: Conceptualization; Data curation; Funding acquisition; Investigation; Methodology; Supervision; Visualization; Writing - original draft; Writing - review \& editing. LRC: Investigation; Methodology; Visualization; Writing - original draft; Writing - review \& editing. Conflicts of Interest: Authors declare there are no conflicts of interest.

\section{REFERENCES}

Kury, A.B. 2003. Annotated catalogue of the Laniatores of the New World (Arachnida, Opiliones). Revista Ibérica de Aracnología, volume especial monográfico, 1: 1-337.

Kury, A.B. 2014. Why does the Tricommatinae position bounce so much within Laniatores? A cladistic analysis, with description of a new family of Gonyleptoidea (Opiliones, Laniatores). Zoological Journal of the Linnean Society, 172: 1-48.

Kury, A.B. \& Alonso-Zarazaga, M.-A. 2011. Addenda and corrigenda to the "Annotated catalogue of the Laniatores of the New World (Arachnida, Opiliones)". Zootaxa, 3034: 47-68.

Kury, A.B. \& Medrano, M. 2016. Review of terminology for the outline of dorsal scutum in Laniatores (Arachnida, Opiliones). Zootaxa, 4097(1): 130-134. D0I

Kury, A.B. \& Orrico, V.G.D. 2006. A new species of Lacronia Strand, 1942 from the highlands of Rio de Janeiro (Opiliones, Gonyleptidae, Pachylinae). Revista lbérica de Aracnologia, 13: 147-153.

Kury, A.B. \& Villarreal M.0. 2015. The prickly blade mapped: establishing homologies and a chaetotaxy for macrosetae of penis ventral plate in Gonyleptoidea (Arachnida, Opiliones, Laniatores). Zoological Journal of the Linnean Society, 174(1): 1-46. DOI

Kury, A.B.; Mendes, A.C.; Cardoso, L.; Kury, M.S.; Granado, A. de A.; Giribet, G.; Cruz-López J.A. \& Longhorn S.J. 2021. World Catalogue of Opiliones. WCOLite version 1.5.8. Available: https://wcolite.com. Access: 11/06/2021.

Maury, E.A. 1993. Gonyleptidae (Opiliones) del bosque subantartico chilenoargentino 3. Descripcion de Osornogyndes, nuevo genero. Boletin de la Sociedad de Biologia de Concepción, 64: 99-104.

Mello-Leitão, C.F. de. 1935a. Alguns novos opiliões do Estado de S. Paulo e do Distrito Federal. Archivos do Museu Nacional, 36(1): 9-37, 26 figs, 1934.

Mello-Leitão, C.F. de. 1935b. Algumas notas sobre os Laniatores. Archivos do Museu Nacional, 36(4): 87-116, 1934.

Soares, B.A.M. 1945. Opiliões da coleção do Museu Nacional do Rio de Janeiro. Arquivos de zoologia do Estado de São Paulo, 4(9): 341-394.

Soares, B.A.M. \& Soares, H.E.M. 1954. Algumas notas sobre opiliões com descrição de novas formas. Papéis avulsos do Departamento de Zoologia, 11(25): 491-507. 